\title{
Multi-response optimisation of machining aluminium-6061 under eco-friendly electrostatic minimum quantity lubrication environment
}

\author{
Muhammad Jamil, Aqib Mashood Khan*, \\ Ning He, Liang Li and Wei Zhao
}

Nanjing University of Aeronautics and Astronautics (NUAA), Nanjing, China

Email: Engr.jamil@nuaa.edu.cn

Email:dr.aqib@nuaa.edu.cn

Email: drnhe@nuaa.edu.cn

Email: liliang@nuaa.edu.cn

Email: nuaazw@nuaa.edu.cn

*Corresponding author

\section{Shoaib Sarfraz}

Manufacturing Department,

School of Aerospace, Transport and Manufacturing,

Cranfield University,

Cranfield, Bedfordshire, MK43 0AL, UK

Email: Shoaib.sarfraz@cranfield.ac.uk

\begin{abstract}
The emerging grave consequences of conventional coolants on health, ecology and product quality, have pushed the scientific research to explore eco-friendly lubrication technique. Electrostatic minimum quantity lubrication (EMQL) has been underscored as a burgeoning technology to cutdown bete noire impacts in machining. This research confers the adoption of a negatively charged cold mist of air-castor oil employed in turning of aluminium-6061T6 material by varying the cutting conditions, as per experimental designed through response surface methodology (RSM). For comprehensive sagacity, a range of cutting speed, feed, depth of cut and EMQL-flow rate were considered. Material removal rate, tool life, surface roughness and power consumption of machine tool were adopted as performance measures. To satisfy multi-criterion simultaneously, RSM-based grey relational analysis (GRA) was employed for multi-objective optimisation. Highest proportion of grey relational grade (GRG) as a single desideratum response function, provided a trade-off between performance measures with $15.56 \%$ improvement in GRG.
\end{abstract}

Keywords: tool life; surface roughness; energy consumption; sustainable manufacturing; RSM-based grey relational analysis; grey relational analysis; GRA.

doi: 10.1504/IJMMM.2019.10023118

Copyright (C) 2019 Inderscience Enterprises Ltd. 
Reference to this paper should be made as follows: Jamil, M., Khan, A.M., He, N., Li, L., Zhao, W. and Sarfraz, S. (2019) 'Multi-response optimisation of machining aluminium-6061 under eco-friendly electrostatic minimum quantity lubrication environment', Int. J. Machining and Machinability of Materials, Vol. 21, Nos. 5/6, pp.459-479.

Biographical notes: Muhammad Jamil is a PhD Research Scholar in the field of mechanical manufacturing. He is Researcher and member of Advanced Cutting Technology (ACT) group at the forefront of the manufacturing and machining technology in close cooperation with the aerospace industry.

Aqib Mashood Khan is a PhD Research Scholar in the field of mechanical manufacturing. He has a firm grip on advance machining with the latest lubrication techniques, nano-particles-based machining, and near-to-dry machining.

Ning He is a well-known Professor in the field of the machining process. He is the Chairman of the research group 'Advanced Cutting Technology (ACT)'. He has completed many projects at domestic and international level.

Liang Li is a member of Advanced Cutting Technology (ACT) and Machining Committee in Aviation Industry Corporation. $\mathrm{He}$ is also the member of Aviation Key Laboratory of Science and Technology. His primary focus is on machinability of difficult to cut materials.

Wei Zhao is a Principal Investigator of sis programs supported by NUAA, Doctoral Fund of Ministry of Education of China, National Natural Science Foundation of China (NSFC). He leads three sub-projects supported by NSFC, National Program on Key Basic Research Project.

Shoaib Sarfraz is a PhD Research Scholar at the Department of Manufacturing, Cranfield University, UK. His current research interest is an innovative cost modelling system development for advance machining processes.

\section{Introduction}

The manufacturing industry is one of the dominant economy-developing sectors that renovate the raw material into valuable products. The sustainable manufacturing has been conceived as a dynamic relationship between technology, quality production, and economics (Schultheiss et al., 2013). The implication of input parameters on key aspects such as cost (Shehab and Abdalla, 2001) quality (Kiyak and Cakır, 2007) and productivity (Raja and Baskar, 2012) have previously been explored while ignoring the environmental impacts of energy consumed by the machine tools.

Aluminium 6061-T6 is a hardening alloy having pertinence applications in aerospace and automotive industries due to excellent strength, weldability, and corrosion resistant. Some typical applications of AISI 6061-T6 include marine fitting, valves, couplings, brake components, and nuclear power radiators (Zhang et al., 2018; Lee and Tang, 2014).

Mechanical machines such as turning and milling are the cardinal equipment in the manufacturing industry that consumes a considerable amount of electrical energy. According to the Energy Information Administration (EIA) statistics, mechanical machines consume above $50 \%$ of the total manufacturing electrical energy (Liu et al., 
2018). The high-reaching prices of energy units and emerging sustainable manufacturing concepts have pushed the industries towards the trail of minimising the energy usage in perspective of cost and eco-friendly. The energy efficiency was conceived with a core determination is to save energy, resources, and ultimately production cost. Moreover, precise evaluation of energy consumed by the individual machine tool is also one of the critical decisions towards appropriate machine selection and preventive procurement decisions. Apropos, there is a dire need in developing economies to improve the machine tool performance and to restrain the industrial waste, energy and resource consumption.

The consolidation of product quality and energy efficient resources is now the benchmarks for the assessment of manufacturing standard for any country. The primeval step of sustainable manufacturing is to cut-down the energy consumption by optimising the material removal rate (MRR), tool life and surface integrity. In this way, it is anticipated to perform machining under acceptable combination of energy consumption, tool life, surface roughness, and MRR. The multitude concepts have been practiced for booming energy efficiency in the industrial sector associated with the high-speed machining. Moreover, the avenue of modelling and experimental techniques (Liu et al., 2018), friction and lubrication aspects for energy reduction have also got attention such as mineral oil lubrication. In some sever machining conditions, material hardness increases cutting forces and power consumption.

The mineral oil-based conventional cooling has been conceived as a fountainhead in the arena of lubrication, commonly practiced in the manufacturing industry to get improved surface quality and longer tool life. However, the mineral oil-based issues such as toxicity (Debnath et al., 2014), dermatitis, respiratory disorder, continuous deterioration of mineral oil in storage, maintenance of cooling pumps, liquid cost increases the overall production cost, which limits their use (Kajaria et al., 2012). According to the sentiment of Occupational Safety and Health Administration (OSHA) and National Institute for Occupational Safety and Health (NIOSH), $5 \mathrm{mg} / \mathrm{m}^{3}$ concentration of mineral oil is permissible. However, only the manufacturing industries in the USA use $20-90 \mathrm{mg} / \mathrm{m}^{3}$ concentration under conventional flood cooling (Boubekri and Shaikh, 2015). The ecological and shop-floor implication of cutting fluids have been summarised in the form of ramification provided in Figure 1.

Figure 1 The impact of metal cutting fluids on our ecology and shop floor (see online version for colours)

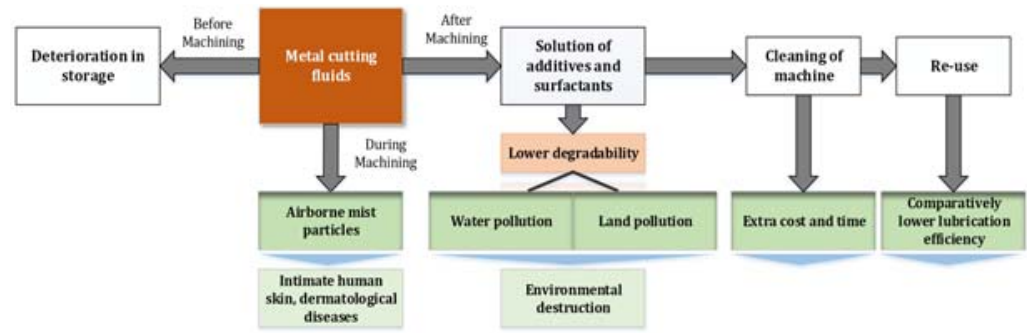

In a global competitive market, ultimate-consumer of the cutting fluid has the core attentions on pursue the cost control and advanced machining. Consequently, a closer 
look at the cost of cutting fluids, dry machining has been identified as an alternative to flood machining where no lubrication and cooling pump are required during the machining operation, as a consequence, overall low energy utilisation in machining. Surprisingly, some complexities are also accompanied with dry machining, for instance, high-temperature elevation led to accelerated tool wear, especially in the machining of high-strength metals and alloys (Sharma and Sidhu, 2014). Genuinely speaking, high machinability and production quality priorities have significantly diminished the application of dry machining in the manufacturing industry.

The near-to-dry machining techniques have reiterated as micro-lubrication and steadfast to cope up with the current necessities of sustainable manufacturing. The role of these techniques have been manifested in perspective of energy consumption (Astakhov, 2010), tool life, surface integrity (Dhar et al., 2007) and MRR (Gaitonde et al., 2008) specifically for difficult-to-cut materials. Minimum quantity lubrication (MQL) is a promising technique that supplies an excellent mixture of an oil-air to dispense a minute quantity at the tool-workpiece interface. In comparison with dry machining, MQL technique cosmetically reduced the temperature and friction as well (Sharma and Sidhu, 2014). Dhar et al. (2006) also explored the likely consequences of MQL during the turning of AISI-1040 steel, and justified as an alternative to dry machining. Khan et al., 2009 mentioned MQL as an environmental-friendly technique with 10,000 times less lubricant in comparison with the conventional cooling during the machining of AISI-9310.

However, there are some complexities also associated with this technology such as low material removal volume and confined cooling effectiveness (Nguyen et al., 2012).

Considering the minimum environmental impact of machining, electrostatic minimum quantity lubrication (EMQL) has a synergistic impact due to negatively charged spray that penetrates into the machine zone effectively (Huang et al., 2015). Under consideration of all the concerns of machining, this novel technology has provided fine quantity of fluid, negative charged mist, employed with ease and within the minimum available time. Huang et al. (2017) have studied the tribological properties of EMQL on stainless steel under milling process. Results highlighted a significant reduction in tool wear and friction coefficient along with the minimum lubrication consumption. However, there is a need to evaluate the performance of EMQL for different machining processes.

Several statistical techniques, such as, response surface methodology (RSM), Taguchi method, grey relational analysis (GRA) and artificial neural network (ANN) have been employed successfully by various researchers to design the experiments and to perform the analysis. Nevertheless, RSM has been underscored as a practical approach to construct a regression relation and to get an optimum cutting condition.

This research work aims to cover the cutting conditions and lubrication effects of EMQL by establishing the fundamentals of this technique specifically for difficult to cut materials such as AISI-6061 T6, to reduce the power consumption; while at the same time, improving the MRR, surface finish, and tool life. This study also presents the multi-objective optimisation of cutting parameters to simultaneously minimise the responses using central composite design (CCD)-based GRA. The grey relational grade (GRG) was applied to determine a trade-off for all performance variables. Empirical models were developed to predict the simultaneous effects of input parameters on an individual output response. Additionally, analysis of variance (ANOVA) has been 
performed to find the contribution of each input parameter and the reliability of the model.

\section{Experimental design and machining}

This section briefly enlightens the workpiece material, composition, experimental setup, lubrication technique, cutting conditions and responses measurement in the context of sustainable manufacturing to understand a complete apprehension of the process setup. The quality of the machining has been assured under controlled parameters. The characteristics of the machining are influenced by two types of parameters; the cutting conditions, and coolant/lubrication parameters.

\subsection{Machine tool and workpiece material}

Titanium-based aluminium alloy (AISI-6061 T6) workpiece material was selected to conduct this study. Before running experiments, samples of length $125 \mathrm{~mm}$ and $45 \mathrm{~mm}$ diameter have been prepared with desired hardness of $\sim 95 \mathrm{HB}$ (Brinell hardness). The chemical composition and physical properties of the workpiece material are enlisted below in Tables 1 and 2, respectively.

Table 1 Chemical Composition of the work material

\begin{tabular}{ccccccccc}
\hline \multicolumn{10}{c}{ Percentage weight } \\
\hline $\mathrm{Al}$ & $\mathrm{Cr}$ & $\mathrm{Cu}$ & $\mathrm{Fe}$ & $\mathrm{Mg}$ & $\mathrm{Mn}$ & $\mathrm{Si}$ & $\mathrm{Ti}$ & $\mathrm{Zn}$ \\
\hline 95.8 & 0.05 & 0.24 & 0.2 & 0.93 & 0.01 & 0.66 & 0.013 & 0.15 \\
\hline \multicolumn{1}{c}{ Source: } & Lee and Tang (2014) & & & & &
\end{tabular}

Table 2 Mechanical properties of the workpiece material

\begin{tabular}{lccccc}
\hline $\begin{array}{l}\text { Test } \\
\text { temperature }\end{array}$ & $\begin{array}{l}\text { Ultimate tensile } \\
\text { strength }(\mathrm{MPa})\end{array}$ & $\begin{array}{c}\text { Yield strength } \\
(\mathrm{MPa})\end{array}$ & $\begin{array}{c}\text { Modulus of } \\
\text { elasticity }(\mathrm{GPA})\end{array}$ & $\begin{array}{c}\text { Fatigue } \\
\text { strength }(\mathrm{MPa})\end{array}$ & $\begin{array}{c}\text { Hardness } \\
(\mathrm{HB})\end{array}$ \\
\hline $25^{\circ} \mathrm{C}$ & 310 & 276 & 68.9 & 96.5 & 95 \\
\hline
\end{tabular}

The conventional lathe machine with a motor power of $10 \mathrm{hp}$ and maximum cutting speed of 5,500 rpm was used to turn the samples. The carbide tools T304-AL H10 Sandvik manufactured had a nose radius of $0.4 \mathrm{~mm}$ and clearance angle of $7^{\circ}$ were used for the turning process.

\subsection{Cutting conditions and EMQL system}

The machining experiments were performed through technically adapted parameters such as; cutting speed, feed, depth of cut and EMQL flow rate (Debnath et al., 2016; Mia et al., 2018; Varghese et al., 2017). The higher and lower ranges of the parameters were selected based on trial runs and the cutting tool catalogues keeping in view the stiffness and compliance of the machine. Each parameter range was segregated into five levels provided in Table 3. The performance measures selection is grounded on the fact that the surface roughness defines the machined product quality whereas the efficient machining reflects the MRR, tool life and energy consumption. In turn, the environmentally 
sustainable machining can be most dominantly attained by optimising influencing parametric effects.

Table 3 Cutting parameters used for turning operation

\begin{tabular}{|c|c|c|c|c|c|c|c|}
\hline \multirow{2}{*}{\multicolumn{2}{|c|}{ Factors }} & \multirow{2}{*}{ Units } & \multicolumn{5}{|c|}{ Levels } \\
\hline & & & $-\alpha$ & -1 & 0 & 1 & $+\alpha$ \\
\hline A & Cutting speed & $\mathrm{m} / \mathrm{min}$ & 30 & 90 & 150 & 210 & 270 \\
\hline B & Feed & $\mathrm{mm} / \mathrm{rev}$ & 0.1 & 0.15 & 0.2 & 0.25 & 0.3 \\
\hline $\mathrm{C}$ & Doc & $\mathrm{mm}$ & 0.3 & 0.4 & 0.5 & 0.6 & 0.70 \\
\hline $\mathrm{D}$ & EMQL flow rate & $\mathrm{ml} / \mathrm{h}$ & 100 & 120 & 140 & 160 & 180 \\
\hline
\end{tabular}

EMQL provided wet-able and penetrating fine drops mixed with a biodegradable lubricant such as castor oil. The eclectic castor oil has higher viscosity, stable frictional film, thermal oxidation stability, superior lubrication, and economical among the vegetable oils of same carbon chain length (Prasenjit et al., 2008; Drown et al., 2001). Thus, castor oil was mixed with air through a nozzle having air pressure of $2 \mathrm{MPa}$ and charge voltage of $-4 \mathrm{kV}$, sprayed into the workpiece-tool interface. The compressed air was provided through a compressor using an air hose to atomise the lubricant. This lubrication system contains high negative charged micron size droplets and a precise lubricating nozzle. The needle of the nozzle operated as a cathode, while workpiece was anode (ground terminal). The orifice of the nozzle was $1 \mathrm{~mm}$ diameter and kept at least $25 \mathrm{~mm}$ far from the cutting zone. In electrostatic MQL, the charged droplets impinged on the cutting zone due to their higher surface adhesive forces (Huang et al., 2015). A schematic diagram of the experimental setup is provided in Figure 2.

Figure 2 Experimental setups for EMQL in the turning process (see online version for colours)

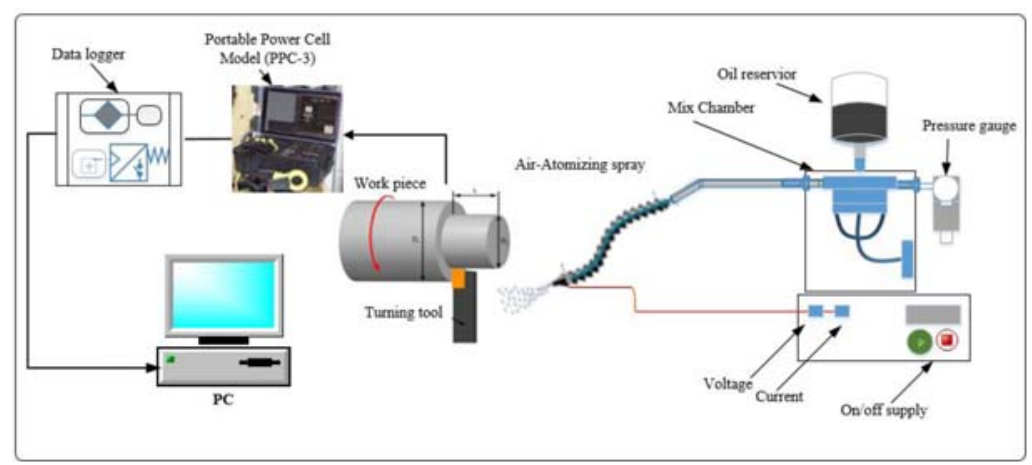

\subsection{Responses measurement}

For each experiment, the machining power was measured at the main supply of the machine tool, using the LabVIEW interface during the idle and the cutting state. Finally, the numeric program was started with the movement of the machining spindle and cutting tool. As all the commands were executed, the spindle returned to the original position; a 
data acquisition system was stopped for an individual experimental run. Moreover, the tool flank wear $\left(V_{B}\right)$ of $0.2 \mathrm{~mm}$ was considered as tool life criterion using SteREODiscovery.V20 zooming microscope. Surface roughness was measured using a Mitutoyo SJ-410 roughness meter from three different locations to reduce the uncertainty.

\section{Results and discussions}

Based on control parameters and each having five levels, a class of RSM named central composite design (CCD) was employed to accomplish the design of experiments (DOE) under EMQL cutting environment. The CCD provided a random combination of 30 experiments with four parameters and each having five levels. Experimental design including input parameters, parametric conditions, and measured response variables are provided in Table 4.

\subsection{D response surface plots for parameters evaluation}

The current challenges of modern industry are mainly to achieve the higher machinability, tool life, and surface quality with lesser energy consumed by the machine tool to relate the machining with sustainable manufacturing. Four parameters were taken into consideration as input parameters: cutting speed, feed, depth of cut and EMQL flow rate to analyse the effect of cutting conditions and lubrication flow rate on experimental results.

\subsubsection{Material removal rate}

The removal of material volume per revolution is the product of cutting speed, feed and depth of cut in the turning process. The machinability in perspective of MRR in the machine tool has been enlisted in Table 4 .

Table 4 Central composite design with input parameters and measured response variables

\begin{tabular}{|c|c|c|c|c|c|c|c|c|}
\hline \multirow[b]{2}{*}{$\begin{array}{l}\text { Run } \\
\text { no. }\end{array}$} & \multicolumn{4}{|c|}{ Input parameters } & \multicolumn{4}{|c|}{ Response variables } \\
\hline & $\begin{array}{c}\text { Speed } \\
(\mathrm{m} / \mathrm{min})\end{array}$ & $\begin{array}{c}\text { Feed } \\
(\mathrm{mm} / \mathrm{rev})\end{array}$ & $\begin{array}{l}D O C \\
(\mathrm{~mm})\end{array}$ & $\begin{array}{c}\text { Flow rate } \\
(\mathrm{ml} / \mathrm{h})\end{array}$ & $\begin{array}{c}M R R \\
\left(\mathrm{~mm}^{3} / \mathrm{min}\right)\end{array}$ & $\begin{array}{c}T L \\
(\mathrm{~min})\end{array}$ & $\begin{array}{c}S R \\
(\mu m)\end{array}$ & $\begin{array}{c}\text { Energy } \\
\text { consumption } \\
(W h)\end{array}$ \\
\hline 1 & 90 & 0.15 & 0.4 & 120 & 90 & 6.5 & 4.5 & 1,040 \\
\hline 2 & 210 & 0.15 & 0.4 & 120 & 210 & 5.7 & 3.97 & 1,470 \\
\hline 3 & 90 & 0.25 & 0.4 & 120 & 150 & 4.12 & 5.2 & 1,176 \\
\hline 4 & 210 & 0.25 & 0.4 & 120 & 350 & 2.61 & 4.6 & 1,626 \\
\hline 5 & 90 & 0.15 & 0.6 & 120 & 135 & 4.1 & 5.22 & 1,383 \\
\hline 6 & 210 & 0.15 & 0.6 & 120 & 315 & 1.73 & 4.68 & 1,787 \\
\hline 7 & 90 & 0.25 & 0.6 & 120 & 225 & 3.63 & 5.92 & 1,489 \\
\hline 8 & 210 & 0.25 & 0.6 & 120 & 525 & 1.32 & 5.25 & 2,017 \\
\hline 9 & 90 & 0.15 & 0.4 & 160 & 90 & 6.69 & 2.1 & 1,014 \\
\hline 10 & 210 & 0.15 & 0.4 & 160 & 210 & 5.54 & 1.31 & 1,406 \\
\hline
\end{tabular}

Note: MRR - material removal rate; SR - surface roughness; TL - tool life. 
Table 4 Central composite design with input parameters and measured response variables (continued)

\begin{tabular}{|c|c|c|c|c|c|c|c|c|}
\hline \multirow[b]{2}{*}{$\begin{array}{l}\text { Run } \\
\text { no. }\end{array}$} & \multicolumn{4}{|c|}{ Input parameters } & \multicolumn{4}{|c|}{ Response variables } \\
\hline & $\begin{array}{l}\text { Speed } \\
(\mathrm{m} / \mathrm{min})\end{array}$ & $\begin{array}{c}\text { Feed } \\
(\mathrm{mm} / \mathrm{rev})\end{array}$ & $\begin{array}{l}D O C \\
(\mathrm{~mm})\end{array}$ & $\begin{array}{c}\text { Flow rate } \\
(\mathrm{ml} / \mathrm{h})\end{array}$ & $\begin{array}{c}M R R \\
\left(\mathrm{~mm}^{3} / \mathrm{min}\right)\end{array}$ & $\begin{array}{c}T L \\
\text { (min) }\end{array}$ & $\begin{array}{c}S R \\
(\mu m)\end{array}$ & $\begin{array}{c}\text { Energy } \\
\text { consumption } \\
\text { (Wh) }\end{array}$ \\
\hline 11 & 90 & 0.25 & 0.4 & 160 & 150 & 4.81 & 2.51 & 1,097 \\
\hline 12 & 210 & 0.25 & 0.4 & 160 & 350 & 3.31 & 1.96 & 1,580 \\
\hline 13 & 90 & 0.15 & 0.6 & 160 & 135 & 4.7 & 2.65 & 1,309 \\
\hline 14 & 210 & 0.15 & 0.6 & 160 & 315 & 2.64 & 1.8 & 1,740 \\
\hline 15 & 90 & 0.25 & 0.6 & 160 & 225 & 4.23 & 3.25 & 1,425 \\
\hline 16 & 210 & 0.25 & 0.6 & 160 & 525 & 2.23 & 2.58 & 1,886 \\
\hline 17 & 30 & 0.2 & 0.5 & 140 & 50 & 7.35 & 4.13 & 1,053 \\
\hline 18 & 270 & 0.2 & 0.5 & 140 & 450 & 3.63 & 3.24 & 1,827 \\
\hline 19 & 150 & 0.1 & 0.5 & 140 & 125 & 4.31 & 3.21 & 1,325 \\
\hline 20 & 150 & 0.3 & 0.5 & 140 & 375 & 1.91 & 4.26 & 1,584 \\
\hline 21 & 150 & 0.2 & 0.3 & 140 & 150 & 2.4 & 3.1 & 1,187 \\
\hline 22 & 150 & 0.2 & 0.7 & 140 & 350 & 1.2 & 4.3 & 1,735 \\
\hline 23 & 150 & 0.2 & 0.5 & 100 & 250 & 4.38 & 5.73 & 1,528 \\
\hline 24 & 150 & 0.2 & 0.5 & 180 & 250 & 5.56 & 1.35 & 1,385 \\
\hline 25 & 150 & 0.2 & 0.5 & 140 & 250 & 4.2 & 3.38 & 1,466 \\
\hline 26 & 150 & 0.2 & 0.5 & 140 & 250 & 4.3 & 3.52 & 1,436 \\
\hline
\end{tabular}

Note: MRR - material removal rate; SR - surface roughness; TL - tool life.

\subsubsection{Tool life}

The influence of cutting conditions and lubrication on turning tool has been provided in Figure 3. Figure 3(a) depicts the decreasing tool life with the increasing depth of cut for all cutting speed (90-210 $\mathrm{m} / \mathrm{min}$ ). However, at higher depth of cut immediate decrease in tool life has been observed. On the other hand, increasing cutting speed also reduced the tool life. The similar results were mentioned in literature regarding the traditional machining (Elmunafi et al., 2015). Figure 3(b) demonstrated the effect of feed and flow rate on tool life. 3D surface plot shows the increasing tool life with the decrease of feed. However, with the decrease of flow rate, a gradual decrease in tool life has been observed. The better tool life with micro-lubrication has been related with the effective wettability of the surface, better lubricity and sustainability at the tool-workpiece interface (Tai et al., 2011; Heinemann et al., 2006). 
Figure 3 3D response surface plot for effects of (a) depth of cut and cutting speed and (b) feed and flow rate on tool life (min) (see online version for colours)

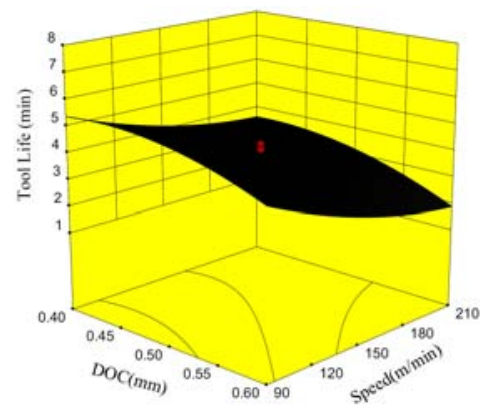

(a)

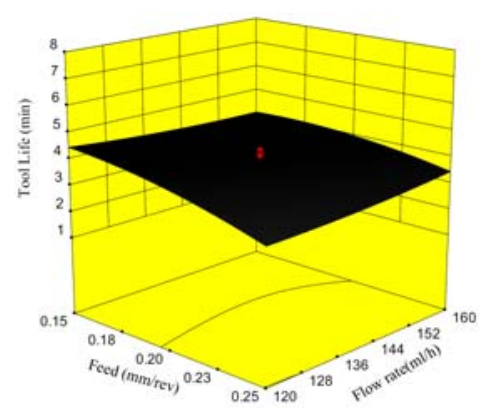

(b)

\subsubsection{Surface roughness}

The effect of machining parameters under EMQL has been investigated to verify the influence on the surface quality of the workpiece illustrated in Figure 4. Figure 4(a) indicates the effect of depth of cut and cutting speed on the surface roughness. The surface roughness decreased with the decrease in the depth of cut. On the other hand, surface roughness decreased with an increase in cutting speed. Vindication of this phenomenon is this that, the reduction of built-up-edges (BUE) possibility may lead to reduction of surface roughness. These results have been justified with the existing literature associated with the processes optimisation (Rajendra and Deepak, 2016). Figure 4(b) shows the interaction effect of feed and EMQL flow rate. The surface roughness decreased with the decreasing feed and increasing the flow rate. In fact, the Leidenfrost effect occurred between the hot surface and the coolant droplets that reduced the heat transfer rate. However, negatively charged EMQL particles were accelerated towards the positively charged tool-workpiece interface by rupturing this effect. Thus, deposition of EMQL particles on the tool-workpiece surface acted as fins that ultimately increased the heat transfer rate during machining.

Furthermore, the presence of high positively charged rake face helps in the capillary suction of coolant sticking at the chip-tool interface. The coolant deeper penetration into the workpiece surface results in better cooling and less spreading of tiny particles in the air. Furthermore, one of the significant limitations of mineral oil-based MQL tiny particles in shop floor environment has been cut-down using this technique (Behera et al., 2017; Suresh et al., 2012). 
Figure 4 3D response surface plot for effects of (a) depth of cut and cutting speed and (b) feed and flow rate on surface roughness $(\mu \mathrm{m})$ (see online version for colours)

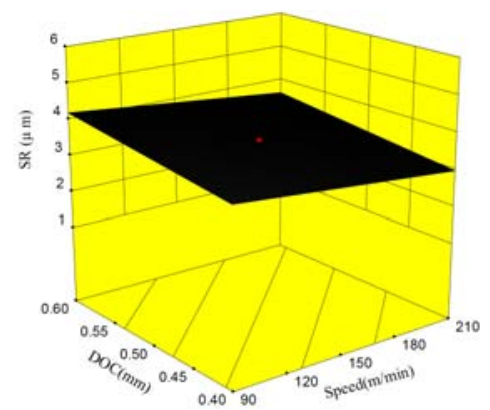

(a)

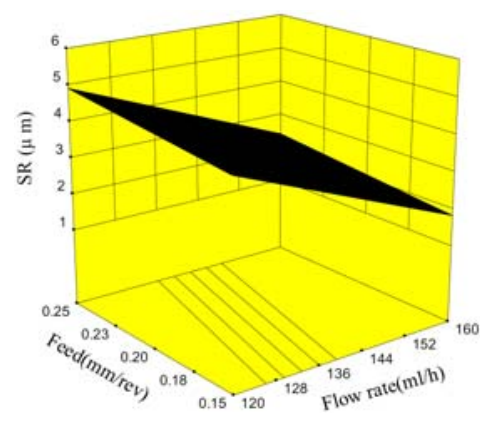

(b)

\subsubsection{Energy consumption}

Figure 5 presented the 3D response plots for energy consumption during the machining of AISI 6061 T6. Figure 5(a) showed the effect of depth of cut and cutting speed on energy consumption. The energy consumed increased with the increasing depth-of-cut and cutting speed. The fact is that; machine tool exerts comparatively higher force to cut the hard material at higher depth of cut. Moreover, the increasing cutting spindle also consumes a significant amount of energy to rotate the workpiece at a higher speed (Camposeco-Negrete, 2015). Figure 5(b) shows the effect of feed and flow rate on the energy consumption. The higher feed increased the energy consumption due to higher cutting forces associated with the tool movement. While on the other hand, lubrication reduced the frictional force that ultimately reduced the energy consumption (Zhang et al., 2015).

Figure 5 3D response surface plot for effects of (a) depth of cut and cutting speed and (b) feed and flow rate on energy consumption (Wh) (see online version for colours)

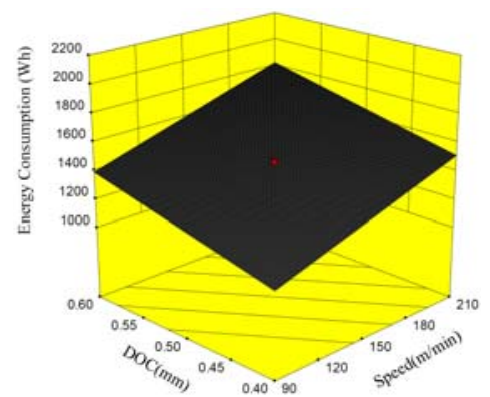

(a)

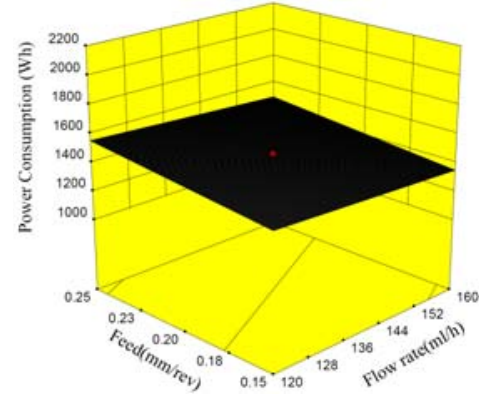

(b) 


\subsection{Development of mathematical models}

RSM is an empirical modelling technique employed to evaluate the relationship between input parameters and individual output response in the form of multiple regression. Regression analysis has been performed to model the response variables (MRR, surface roughness, tool wear, power consumption) and to determine the optimum level of parameters. This statistical technique also offered the opportunity to check the validity of the model and to predict the pre-experimental output responses. Through the model analysis, a regression equation was derived based on independent process parameters and performance measure to observe the simultaneous effect of input parameters using Design Expert software (8.0.7.1).

$$
Y=\beta_{0}+\sum_{i=1}^{k} \beta_{i} X_{i}+\sum_{i=1}^{k} \beta_{i i} X_{i}^{2}+\sum_{i=1}^{k-1} \sum_{j=i+1}^{k} \beta_{i j} X_{i} X_{j}
$$

where $Y$-predicted response; $\beta_{0}$ - a constant mean; $\beta_{i}$ - linear coefficient; $\beta_{i i}$ - squared coefficient and $\beta_{i j}$ - the interaction coefficient. A higher order regression equation for MRR and tool life, while a linear equation was the best fit for surface roughness and energy consumption are provided in equations (2), (3), (4), (5).

$$
\begin{aligned}
& M R R=250-1.67 \times \text { speed }-1,250 \times \text { feed }-500 \times \text { doc }+8.33 \times \text { speed } \times \text { feed } \\
& +3.33 \times \text { speed } \times \text { doc }+2,500 \times \text { feed } \times \text { doc } \\
& \text { Tool life }=23.10-0.027 \times \text { speed }-41.25 \times \text { feed }+23.75 \times \text { doc } \\
& -0.224 \times \text { flow rate }-0.039 \times \text { speed } \times \text { doc }+97.75 \times \text { feed } \times \text { doc } \\
& +0.05 \times \text { doc } \times \text { flow rate }+1.132 \times 10^{-4} \times \text { speed }^{2}-75.08 \times \text { feed }^{2} \\
& -51.52 \times \text { doc }^{2}+6.93229 \times 10^{-4} \times \text { flow rate }^{2} \\
& \text { Surface roughness }=10.286-4.84722 \times 10^{-3} \times \text { speed }+5.95 \times \text { feed } \\
& +3.167 \times \text { doc }-0.0624 \times \text { flow rate } \\
& \text { Power consumption }=106.20+3.56 \times \text { speed }+1,387.5 \times \text { feed } \\
& +1,551.25 \times \text { doc }-1.7 \times \text { flow rate }
\end{aligned}
$$

\subsection{Multiple response optimisation using GRA}

For the evaluation and the optimisation of cutting conditions, multi-response optimisation provided a trade-off between different responses. GRA is a measuring portion of the grey system theory that determines some uncertain relationships between one main factor (GRA) and included all the other factors (input and output parameters). It is the actual measurement of the absolute data differences that can be used to approximate the correlations (Huang et al., 2015). Data pre-processing is a common step, typically applied when the range, units, and the direction of targets are different. It is actually a process of altering the original sequence to a comparable single sequence to handle multiple responses shown in Figure 6. 
Figure 6 A schematic diagram to clarify the vital purpose of GRA (see online version for colours)

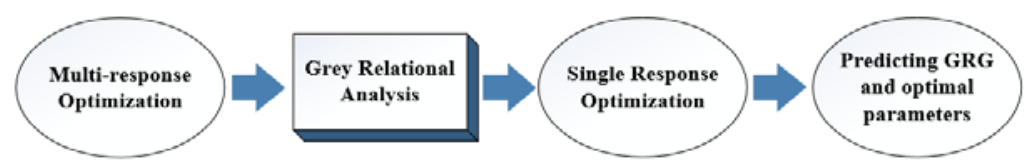

Several methods are commonly used for data sequence for the GRA. If the target response variables are infinite, then we can apply larger the better in get a normalised form equation (6).

$$
X_{i}^{*}(n)=\frac{X_{i}^{o}(n)-\min X_{i}^{o}(n)}{\max X_{i}^{o}(n)-\min X_{i}^{o}(n)}
$$

If the original sequence has a target response variable lower the better characteristic in a normalised form equation (7):

$$
X_{i}^{*}(n)=\frac{\max X_{i}^{o}(n)-X_{i}^{o}(n)}{\max X_{i}^{o}(n)-\min X_{i}^{o}(n)}
$$

After achieving a definite target value, the original sequence can be normalised equation (8).

$$
X_{i}^{*}(n)=1-\frac{X_{i}^{o}(n)-X^{O}}{\max X_{i}^{o}(n)-X^{O}}
$$

where $i=1, \ldots, z$, where $z$ is the experimental trial and $n=1, \ldots, k$. Here, $k$ is the total involved parameters. $X_{i}^{o}(n)$ : original data sequence, $X_{i}^{*}(n)$ : pre-processing sequence, $\max X_{i}^{o}(n)$ : highest value of $X_{i}^{o}(n), \min X_{i}^{o}(n)$ : lowest value of $X_{i}^{o}(n)$ and $X^{O}$ is the desired target value.

Moreover, relationship between experimental normalised values and predicted values were defined through grey relational coefficient (GRC) $\xi_{i}^{*}(n)$ is assigned to individual response. After data pre-processing, the grey relational coefficient $\xi_{i}(n)$ for the $n^{\text {th }}$ parameter and $i^{\text {th }}$ experiment can be expressed in equation (9).

$$
\xi_{i}^{*}(n)=\frac{\Delta_{\min }+\xi \times \Delta_{\max }}{\Delta_{o i}(n)+\xi \times \Delta_{\max }}
$$

where $\Delta_{o i}(n)$ is the deviation of sequence from the reference sequence. The value of identification coefficient $\xi$ varies between 0 and 1 to lower the effect of $\Delta_{\max }=1$, that enlarged the grey relational coefficient. Generally, the value of $\xi$ is taken the value as 0.5 to fit into the GRC equation. However, grey relational grade (GRG) is a relationship between experimental values and normalised values. The higher GRG indicates process parameter closer to the optimal value can be defined in equation (10).

$$
\gamma_{i}=\frac{1}{k} \sum_{n=1}^{k} \xi_{i}(n)
$$


where $\gamma_{i}$ represents the level of correlation between the original sequence and comparable sequence. If two sequences are the same, it depicts both have GRG equal to one (Huang et al., 2017). In the last step, GRC and GRG were calculated using equations (9) and (10) provided in Table 5 .

Table 5 Grey relational coefficient and grey relational grade values

\begin{tabular}{lccccc}
\hline Sr. no. & GRC-MRR & GRC-SR & GRC-TL & GRC-Power & GRG \\
\hline 1 & 0.3532 & 0.4195 & 0.7834 & 0.9507 & 0.627 \\
2 & 0.4299 & 0.4642 & 0.6508 & 0.5238 & 0.517 \\
3 & 0.3878 & 0.3721 & 0.4877 & 0.7558 & 0.501 \\
4 & 0.5758 & 0.4120 & 0.3935 & 0.4504 & 0.458 \\
5 & 0.3785 & 0.3709 & 0.4862 & 0.5761 & 0.453 \\
6 & 0.5307 & 0.4062 & 0.3537 & 0.3935 & 0.421 \\
7 & 0.4419 & 0.3333 & 0.4525 & 0.5136 & 0.435 \\
8 & 1.0000 & 0.3691 & 0.3377 & 0.3333 & 0.510 \\
9 & 0.3532 & 0.7447 & 0.8233 & 1.0000 & 0.730 \\
10 & 0.4299 & 1.0000 & 0.6295 & 0.5613 & 0.655 \\
11 & 0.3878 & 0.6576 & 0.5476 & 0.8580 & 0.613 \\
12 & 0.5758 & 0.7800 & 0.4322 & 0.4698 & 0.564 \\
13 & 0.3785 & 0.6324 & 0.5371 & 0.6296 & 0.544 \\
14 & 0.5307 & 0.8247 & 0.3950 & 0.4086 & 0.540 \\
15 & 0.4419 & 0.5430 & 0.4964 & 0.5496 & 0.508 \\
16 & 1.0000 & 0.6448 & 0.3752 & 0.3651 & 0.596 \\
17 & 0.3333 & 0.4498 & 1.0000 & 0.9278 & 0.678 \\
18 & 0.7600 & 0.5443 & 0.4525 & 0.3815 & 0.535 \\
19 & 0.3725 & 0.5482 & 0.5029 & 0.6172 & 0.510 \\
20 & 0.6129 & 0.4386 & 0.3611 & 0.4680 & 0.470 \\
21 & 0.3878 & 0.5629 & 0.3832 & 0.7435 & 0.519 \\
22 & 0.5758 & 0.4353 & 0.3333 & 0.4102 & 0.439 \\
23 & 0.4634 & 0.3428 & 0.5087 & 0.4938 & 0.452 \\
24 & 0.4634 & 0.9829 & 0.6321 & 0.5748 & 0.663 \\
25 & 0.4634 & 0.5269 & 0.4940 & 0.5260 & 0.503 \\
\hline & & & & &
\end{tabular}

\subsection{Analysis of variance}

The relative importance among the input parameters (speed, feed, depth of cut, EMQL flow rate) for response variables (MRR, tool life, surface roughness, power consumption) needs to be investigated to get optimum level of the parameters. For results interpretation, ANOVA was applied to analyse the model validation by considering the individual and simultaneous effect of input parameters on the response variables. Table 6 shows ANOVA results for linear, quadratic and interaction effects of the parameters. The ANOVA analysis for each parameter affecting GRG pointed out that flow rate, depth of cut, cutting speed and feed are the significant parameters. Furthermore, the flow rate has 
the most significant influence among all other input parameters. The probability value (p-value) was used to find out the significance at $95 \%$ confidence intervals. The p-value of less than 0.05 depicts that particular factor has a significant effect on the model. Some other model-coefficients such as $\mathrm{R}^{2}$ is 0.9544 , 'pred R-squared' of 0.7401 is in reasonable agreement with the 'adj R-squared' of 0.9118 .

Table 6 ANOVA for multi-response variables

\begin{tabular}{ccccccc}
\hline Source & $\begin{array}{c}\text { Sum of } \\
\text { squares }\end{array}$ & $d f$ & $\begin{array}{c}\text { Mean } \\
\text { square }\end{array}$ & Fvalue & $\begin{array}{c}\text { p-value } \\
\text { Prob }>F\end{array}$ & \\
\hline Model & 0.167657 & 14 & 0.011976 & 22.4148 & $<0.0001$ & Significant \\
A speed & 0.007903 & 1 & 0.007903 & 14.79231 & 0.0016 & \\
B feed & 0.006085 & 1 & 0.006085 & 11.38892 & 0.0042 & \\
C doc & 0.027962 & 1 & 0.027962 & 52.33748 & $<0.0001$ & \\
D flow rate & 0.065223 & 1 & 0.065223 & 122.0801 & $<0.0001$ & \\
AB & 0.005375 & 1 & 0.005375 & 10.06093 & 0.0063 & \\
AC & 0.010134 & 1 & 0.010134 & 18.96723 & 0.0006 & \\
AD & 0.000307 & 1 & 0.000307 & 0.575098 & 0.4600 & \\
BC & 0.014681 & 1 & 0.014681 & 27.4791 & $<0.0001$ & \\
BD & 0.000349 & 1 & 0.000349 & 0.653557 & 0.4315 & \\
CD & 0.00052 & 1 & 0.00052 & 0.973193 & 0.3395 & \\
$\mathrm{~A}^{2}$ & 0.021857 & 1 & 0.021857 & 40.9108 & $<0.0001$ & \\
$\mathrm{~B}^{2}$ & $1.6 \mathrm{E}-05$ & 1 & $1.6 \mathrm{E}-05$ & 0.029934 & 0.8650 & \\
$\mathrm{C}^{2}$ & 0.000348 & 1 & 0.000348 & 0.651206 & 0.4323 & \\
$\mathrm{D}^{2}$ & 0.007131 & 1 & 0.007131 & 13.34752 & 0.0024 & \\
Residual & 0.008014 & 15 & 0.000534 & & & \\
Pure error $_{\text {Cor total }}$ & 0.000116 & 5 & $2.32 \mathrm{E}-05$ & & & \\
\hline $\mathrm{R}^{2}=0.9544$ & 0.175671 & 29 & & & & \\
\hline
\end{tabular}

GRG values derived from grey relation coefficient (GRC), are always desired as a maximum the better. For multi-objective optimisation, GRA is applied to investigate the simultaneous effect of several variables (Khan et al., 2018). The optimum GRG value does not define individual response values, it represents the trade-off between all response variables. A GRG regression model was established based on a single response of GRG and process parameters using the output from all the responses in equation (11).

$$
\begin{aligned}
\text { GRG }= & 2.12922-6.48526 \times 10^{-3} \times \text { speed }-3.48786 \times \text { feed }-1.42696 \times \text { doc } \\
& -6.8687 \times 10^{-3} \times \text { flow rate }+6.10967 \times 10^{-3} \times \text { speed } \times \text { feed } \\
& +4.19441 \times 10^{-3} \times \text { speed } \times \text { doc }+3.6518 \times 10^{-6} \times \text { speed } \times \text { flow rate } \\
& +6.05830 \times \text { feed } \times \text { doc }+4.67155 \times 10^{-3} \times \text { feed } \times \text { flow rate } \\
& -2.85029 \times 10^{-3} \times \text { doc } \times \text { flow rate }+7.84142 \times 10^{-6} \times \text { speed }^{2} \\
& -0.30543 \times \text { feed }^{2}-0.5615 \times \text { doc }^{2}+4.03105 \times 10^{-5} \times \text { flow rate }^{2}
\end{aligned}
$$


The response surface graphs (Figure 7) depict the effect of parameters on the GRG. The following figures consider the simultaneous effect of two parameters at the centre values of other parameters. Figure 7(a) combines the effect of feed and cutting speed on GRG. It shows that GRG gradually increased with the decreasing feed when speed is low (90 $\mathrm{m} / \mathrm{min})$. However, its effect on GRG is marginal when cutting speed is high $(210 \mathrm{~m} / \mathrm{min})$. While, GRG decreased with the decreasing cutting speed from $210-150 \mathrm{~m} / \mathrm{min}$. However, GRG increased on the further decrease in cutting speed.

Figure 7(b) has shown the simultaneous effect of depth of cut and cutting speed on GRG. A continuous increase in GRG has been observed with the decrease in depth of cut up to the minimum level $(0.4 \mathrm{~mm})$. On the other hand, the behaviour of GRG for cutting speed was same as observed previously [Figure 7(a)]. The simultaneous effect of both parameters (maximum GRG) has been observed at the lowest level of both parameters.

The three-dimensional behaviour of GRG observed, by varying the cutting speed and EMQL flow rate. When the cutting speed is low, GRG is highly sensitive to EMQL flow rate, as depicted in Figure 7(c) decreased in flow rate sharply reduced the GRG. However, this reduction of GRG becomes smaller and smaller with the decrease of cutting speed up to the middle level of cutting speed, and it increased further with the decrease of cutting speed. It was also observed that GRG variation is minimum at higher values of cutting speed.

Figure 7(d) illustrated the interaction effect of depth of cut and feed on the GRG. From the illustration, it depicts that GRG increased in high rate with the decrease in depth of cut, at the minimum feed $(0.15 \mathrm{~mm} / \mathrm{rev})$. However, there was a significant increase in GRG has been observed at the higher level of feed $(0.25 \mathrm{~mm} / \mathrm{rev})$. On the other hand, GRG was increasing linearly with the decrease of feed at the lower level of depth of cut. While, at the higher level of depth of cut, it was vice versa. The highest GRG was achieved at the lower level of depth of cut and feed. For this condition, depth of cut has a significant effect on GRG as compared to feed.

The next analysis is the interaction effects of flow rate and feeds on GRG provided in the 3D surface plot shown in Figure 7(e). As shown, an accelerated reduction in GRG has been observed with the decreasing flow rate. Conversely, GRG was increased with the decrease of feed. However, it can be observed from the plot that GRG is more sensitive to flow rate and less sensitive to feed. The overall highest GRG was achieved at the lower level of feed and a higher level of flow rate.

Finally, the effect of the 3D relationship of flow rate and depth of cut on GRG has been presented in Figure 7(f). It can be observed that GRG value increased actively with the increase in flow rate at the low level of depth of cut. While in the conditions of the depth of cut, GRG was also increased, however, the rate of increase was slower as compared to flow rate. The overall maximum effect of both parameters can be observed in results of GRG, at the highest level of flow rate and a minimum level of depth of cut. EMQL flow rate has the highest percentage contribution on GRG.

From the above discussion and plots provided in Figure 7, it follows that the effects of parameters on GRG are highly interactive and complex. The presented plots can provide a guideline to process the material with the desired GRG. The plots show that one should process the material with lower feed, low speed, low depth of cut and high flow rate to realise the maximum GRG. 
Figure 7 Response surface plots for the effect of process parameters on grey relational grade, (a) feed vs. speed (b) the depth of cut vs. speed (c) fluid flow rate vs. speed (d) feed vs. depth of cut (e) feed vs. fluid flow rate (f) depth of cut vs. fluid flow rate (see online version for colours)

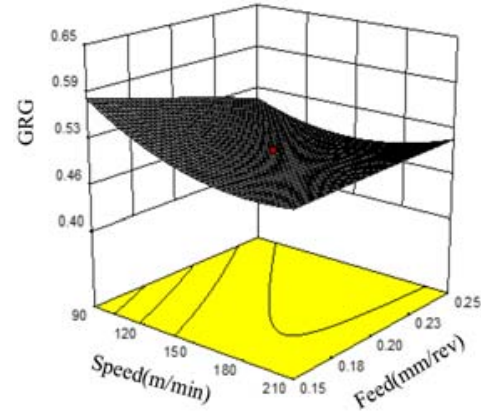

(a)

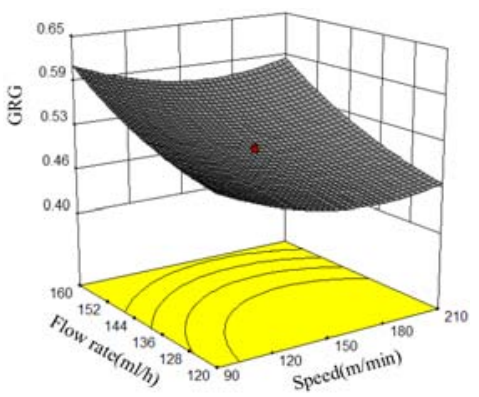

(c)

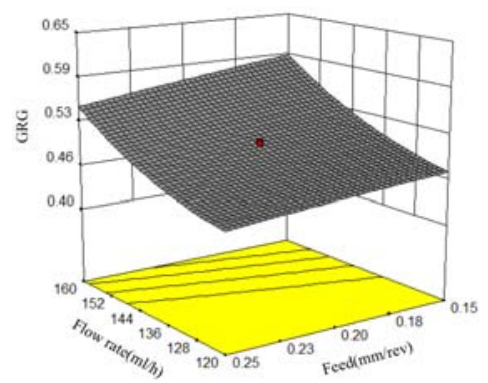

(e)

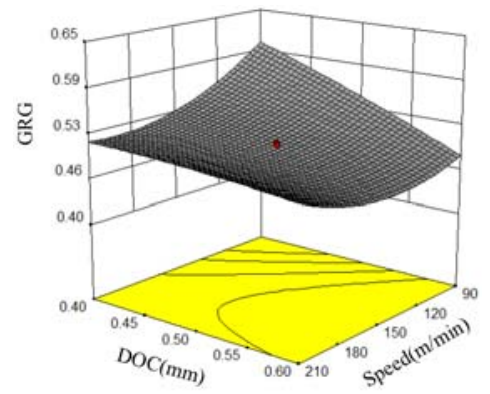

(b)

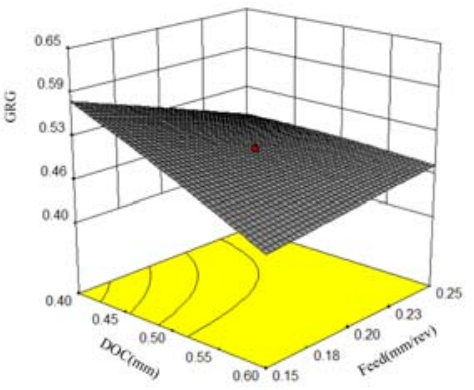

(d)

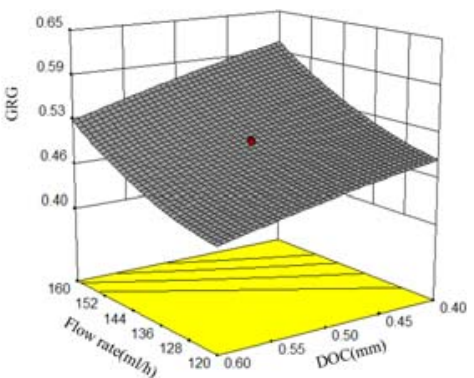

(f) 


\section{Prediction of GRG and optimum cutting conditions}

The equal weight grey relational grade was considered for all the sequence and taken as a single response to determining the optimum machining conditions and for the confirmation of the experiments. The GRG has always considered under larger the better characteristics that indicate the performance of that particular experiment. The GRG obtained under equation (10) was analysed for further analysis. ANOVA was performed to check the significance of influencing parameters, interaction effect, and the model-error. Experiments were conducted to confirm the validation of the models experimentally. Six confirmatory experiments were conducted with randomly chosen input variables (different from CCD employed for a model) within the parameters range.

After evaluating the optimal cutting conditions by highest GRG, the final step is to predict the better GRG for the optimal cutting conditions. Therefore, the predicted GRG $\gamma_{\text {pred }}$ at the optimal cutting conditions can be described:

$$
\gamma_{\text {pred }}=\gamma_{t m}+\sum_{i=1}^{o}\left(\gamma_{i}-\gamma_{t m}\right)
$$

where $\gamma_{\text {pred }}$ : predicted grey relational grade, $\gamma_{t m}$ : total mean of GRG, and $\gamma_{i}$ : highest average GRG at the specific parameter level. $i=1,2 \ldots, o$, where ' $o$ ' is the number of parameters significantly affect the GRG. Table 6 indicates the comparison between predicted GRG (0.8933) calculated by equation (12) and experimental GRG (0.8434) at optimal combination from the experiment. Multi-responses optimisation results have shown the best combination values at cutting speed of $30 \mathrm{~m} / \mathrm{min}$, the feed of $0.15 \mathrm{~mm} / \mathrm{rev}$, depth of cut of $0.4 \mathrm{~mm}$, and EMQL flow rate of $180 \mathrm{ml} / \mathrm{h}$ for optimum trade-off responses.

Table 7 Predicted grey relational grade for optimal combination and confirmation of results

\begin{tabular}{lccc}
\hline & $\begin{array}{c}\text { Initial machining } \\
\text { combination }\end{array}$ & \multicolumn{2}{c}{ Optimal machining combination } \\
\cline { 3 - 4 } & $\mathrm{A}_{2} \mathrm{~B}_{2} \mathrm{C}_{2} \mathrm{D}_{4}$ & Predicted & Experimental \\
\hline Levels & 90 & $\mathrm{~A}_{1} \mathrm{~B}_{2} \mathrm{C}_{2} \mathrm{D}_{5}$ & $\mathrm{~A}_{1} \mathrm{~B}_{2} \mathrm{C}_{2} \mathrm{D}_{5}$ \\
MRR & 6.69 & & 180 \\
Tool life & 2.1 & & 7.3 \\
Surface roughness & 1,014 & & 1.32 \\
Power consumption & 0.730 & & 1,015 \\
GRG & & 0.8931 & 0.8436 \\
\hline
\end{tabular}

Improvement in grey relational grade $=0.1136$

Percentage improvement in grey relational grade $=15.56 \%$

Note: $\mathrm{A}$ - cutting speed; $\mathrm{B}$ - feed; $\mathrm{C}$ - depth of cut; $\mathrm{D}$ - flow rate.

It has been observed (Table 7) that the net improvement in GRG, from initial cutting condition $\left(\mathrm{A}_{2} \mathrm{~B}_{2} \mathrm{C}_{2} \mathrm{D}_{4}\right)$ to the optimal cutting condition $\left(\mathrm{A}_{1} \mathrm{~B}_{2} \mathrm{C}_{2} \mathrm{D}_{5}\right)$ was 0.1136 , and has good agreement with the available published literature. Multi-objective optimisation was employed using an orthogonal array-based GRA in the high-speed turning of Inconel 718 (Pradhan, 2013). Results showed an improvement of GRG from initial machining condition to final machining conditions was $11.53 \%(.08404 * 100 / 0.72865)$. The machining parameters were optimised in hot turning and achieved optimal parameters by 
improving the grey relation from 0.708 to 0.9184 in experimentation (Ranganathan and Senthilvelan, 2011)

\section{Conclusions}

This research aimed to use the RSM-based GRA to find the trade-off between four matrices under EMQL. The tribological behaviour of cutting speed, feed, depth of cut, and EMQL flow rate on sustainable leading responses (MRR, tool life, surface roughness, and power consumption) were modelled and analysed for multi-objective optimisation. Following are the results derived from the current study.

1 Multi-responses optimisation results have shown the best combination values, i.e., EMQL flow rate $(180 \mathrm{ml} / \mathrm{h})$, depth of cut $(0.4 \mathrm{~mm})$, cutting speed $(30 \mathrm{~m} / \mathrm{min})$ and feed $(0.15 \mathrm{~mm} / \mathrm{rev})$ respectively. For sustainable machining, EMQL flow rate has reduced significant environmental footprints of machining.

2 Empirical regression equations were developed to check the simultaneous effect of input parameters on individual response values. The $\mathrm{R}^{2}$ of 0.9544 depicts that the regression model is reliable to predict the response before experimentation due to high.

3 Another important aspect of this study is the use of biodegradable oil to reduce prevalent shop floor diseases such as respiratory, dermatological and genetic diseases.

4 The improvement of GRG from an initial parametric combination, $\left(\mathrm{A}_{2} \mathrm{~B}_{2} \mathrm{C}_{2} \mathrm{D}_{4}\right)$ to the optimal parametric combination, $\left(\mathrm{A}_{1} \mathrm{~B}_{2} \mathrm{C}_{2} \mathrm{D}_{5}\right)$ is 0.1136 to optimise the input parameters for multiple responses. These are the recommended values of process parameters to minimise the responses concurrently to reduce the environmental impact.

5 It was noticed that the percentage improvement in the grey relational grade is $15.56 \%$. This significant improvement is more supported by the literature.

6 From the ANOVA results of GRG, the percentage contribution of each parameter is in descending order for input parameters is EMQL flow rate, depth of cut, cutting speed and feed respectively. EMQL flow rate is the most significant parameter affecting GRG, for the turning process under EMQL cooling by considering simultaneous reduction of responses. Therefore, it was proposed to substitute electrostatic MQL as a sustainable lubrication technique for the machining process.

EMQL is a useful tool to find a trade-off between productivity and power consumption to make the machining process eco-friendly. However, in machining of Inconel and composite materials, EMQL is still uncertain. Future works may consider the nozzle dimensions, the negative voltage, distance and number of nozzles from the machining zone for different materials to increase the machinability.

The current study encourages the green machining and follows the rule and regulation implemented by ISO500001. 


\section{Acknowledgements}

Muhammad Jamil and Aqib Mashood Khan contributed equally to this work and should be considered as co-first authors.

\section{References}

Astakhov, V.P. (2010) 'Metal cutting theory foundations of near-dry (MQL) machining', International Journal of Machining \& Machinability of Materials, Vol. 7, No. 1, pp.1-16.

Behera, B.C., Alemayehu, H., Ghosh, S. and Rao, P.V. (2017) 'A comparative study of recent lubri-coolant strategies for turning of Ni-based superalloy', Journal of Manufacturing Processes, Vol. 30, pp.541-552.

Bezerra, M.A., Santelli, R.E., Oliveira, E.P., Villar, L.S. and Escaleira, L.A. (2008) 'Response surface methodology (RSM) as a tool for optimization in analytical chemistry', Talanta, Vol. 76, No. 5, pp.965-977.

Boubekri, N. and Shaikh, V. (2015) 'Minimum quantity lubrication (MQL) in machining: benefits and drawbacks', Journal of Industrial and Intelligent Information, Vol. 3, No. 3, pp.205-209.

Camposeco-Negrete, C. (2015) 'Optimization of cutting parameters using response surface method for minimizing energy consumption and maximizing cutting quality in turning of AISI 6061 T6 aluminum', Journal of Cleaner Production, Vol. 91, pp.109-117.

Debnath, S., Reddy, M.M. and Yi, Q. S. (2016) 'Influence of cutting fluid conditions and cutting parameters on surface roughness and tool wear in turning process using Taguchi method', Measurement, Vol. 78, pp.111-119.

Debnath, S., Reddy, M.M. and Yi, Q.S. (2014) 'Environmental friendly cutting fluids and cooling techniques in machining: a review', Journal of Cleaner Production, Vol. 83, pp.33-47.

Dhar, N.R., Ahmed, M.T. and Islam, S. (2007) 'An experimental investigation on the effect of minimum quantity lubrication in machining AISI 1040 steel', International Journal of Machine Tools \& Manufacture, Vol. 47, pp.748-753.

Dhar, N.R., Kamruzzaman, M. and Ahmed, M. (2006) 'Effect of minimum quantity lubrication (MQL) on tool wear and surface roughness in turning AISI-4340 steel', Journal of Materials Processing Technology, Vol. 172, No. 2, pp.299-304.

Drown, D.C., Harper, K. and Frame, E. (2001) 'Screening vegetable oil alcohol esters as fuel lubricity enhancers', Journal of the American Oil Chemists Society, Vol. 78, No. 6, pp.579-584.

Elmunafi, M.H.S., Noordin, M.Y. and Kurniawan, D. (2015) 'Tool life of coated carbide cutting tool when turning hardened stainless steel under minimum quantity lubricant using castor oil' Procedia Manufacturing, Vol. 2, pp.563-567.

Gaitonde, V.N., Karnik, S.R. and Davim, J.P. (2008) 'Selection of optimal MQL and cutting conditions for enhancing machinability in turning of brass', Journal of Materials Processing Technology, Vol. 204, Nos. 1-3, pp.459-464.

Heinemann, R., Hinduja, S., Barrow, G. and Petuelli, G. (2006) 'Effect of MQL on the tool life of small twist drills in deep-hole drilling', International Journal of Machine Tools and Manufacture, Vol. 46, No. 1, pp.1-6.

Huang, S., Lv, T., Xu, X., Ma, Y. and Wang, M. (2017) 'Experimental evaluation on the effect of electrostatic minimum quantity lubrication (EMQL) in end milling of stainless steels', Machining Science and Technology, Vol. 22, No. 2, pp.1-16.

Huang, S., Wang, Z., Yao, W. and Xu, X. (2015) 'Tribological evaluation of contact-charged electrostatic spray lubrication as a new near-dry machining technique', Tribology International, Vol. 91, pp.74-84. 
Kajaria, S., Chittipolu, S., Adera, S. and Hung, W.N. (2012) 'Micro-milling in minimum quantity lubrication', Machining Science and Technology, Vol. 16, No. 4, pp.524-546.

Khan, A.M., Ning, H., Liang, L. and Jamil, M. (2018) 'Comment to paper entitled 'Experimental investigation of machinability characteristics and multiresponse optimization of end milling in aluminium composites using RSM based grey relational analysis', Measurement, 105 (2017) 78-86', Measurement, Vol. 119, pp.175-177.

Khan, M.M.A., Mithu, M.A.H. and Dhar, N.R. (2009) 'Effects of minimum quantity lubrication on turning AISI 9310 alloy steel using vegetable oil-based cutting fluid', Journal of Materials Processing Technology, Vol. 209, pp.5573-5583.

Kiyak, M. and Cakır, O. (2007) 'Examination of machining parameters on surface roughness in EDM of tool steel', Journal of Materials Processing Technology, Vol. 191, Nos. 1-3, pp.141-144.

Lee, W.S. and Tang, Z.C. (2014) 'A relationship between mechanical properties and microstructural response of 6061-T6 aluminum alloy impacted at elevated temperatures', Materials \& Design, Vol. 58, pp.116-124.

Liu, P., Tuo, J., Liu, F., Li, C. and Zhang, X. (2018) 'A novel method for energy efficiency evaluation to support efficient machine tool selection', Journal of Cleaner Production, Vol. 191, pp.57-66.

Mia, M., Dey, P.R., Hossain, M.S., Arafat, M.T., Asaduzzaman, M., Ullah, M.S. and Zobaer, S.T. (2018) 'Taguchi S/N based optimization of machining parameters for surface roughness, tool wear and material removal rate in hard turning under MQL cutting condition', Measurement, Vol. 122, pp.380-391.

Nguyen, T.K., Do, I. and Kwon, P. (2012) 'A tribological study of vegetable oil enhanced by nanoplatelets and implication in MQL machining', International Journal of Precision Engineering and Manufacturing, Vol. 13, No. 7, pp.1077-1083.

Pradhan, M.K. (2013) 'Estimating the effect of process parameters on surface integrity of EDMed AISI D2 tool steel by response surface methodology coupled with grey relational analysis', The International Journal of Advanced Manufacturing Technology, Vol. 67, Nos. 9-12, pp.2051-2062.

Prasenjit, K., Pranay, A. and Hong, L. (2008) 'Formation and characterization of tribofilm', Journal of Tribology, Vol. 130, No. 4, pp.4201-4206.

Raja, S.B. and Baskar, N. (2012) 'Application of particle swarm optimization technique for achieving desired milled surface roughness in minimum machining time', Expert Systems with Applications, Vol. 39, No. 5, pp.5982-5989.

Rajendra, B. and Deepak, D. (2016) 'Optimization of process parameters for increasing material removal rate for turning Al6061 using S/N Ratio', Procedia Technology, Vol. 24, pp.399-405.

Ranganathan, S. and Senthilvelan, T. (2011) 'Multi-response optimization of machining parameters in hot turning using grey analysis', The International Journal of Advanced Manufacturing Technology, Vol. 56, Nos. 5-8, pp.455-462.

Schultheiss, F., Zhou, J., Gröntoft, E. and Ståhl, J.E. (2013) 'Sustainable machining through increasing the cutting tool utilization', Journal of Cleaner Production, Vol. 59, pp.298-307.

Sharma, J. and Sidhu, B.S. (2014) 'Investigation of effects of dry and near dry machining on AISI D2 steel using vegetable oil', Journal of Cleaner Production, Vol. 66, pp.619-623.

Shehab, E.M. and Abdalla, H.S. (2001) 'Manufacturing cost modeling for concurrent product development', Robotics and Computer-Integrated Manufacturing, Vol. 17, No. 4, pp.341-353.

Suresh, R., Basavarajappa, S., Gaitonde, V.N. and Samuel, G.L. (2012) 'Machinability investigations on hardened AISI 4340 steel using coated carbide insert', International Journal of Refractory Metals and Hard Materials, Vol. 33, pp.75-86.

Tai, B.L., Dasch, J.M. and Shih, A.J. (2011) 'Evaluation and comparison of lubricant properties in minimum quantity lubrication machining', Machining Science and Technology, Vol. 15, No. 4, pp.376-391. 
Varghese, L., Aravind, S. and Shunmugesh, K. (2017) 'Multi-objective optimization of machining parameters during dry turning of $11 \mathrm{SMn} 30$ free cutting steel using grey relational analysis', Materials Today: Proceedings, Vol. 4, No. 2, pp.4196-4203.

Zhang, X., Ma, J.W., Jia, Z.Y. and Song, D.N. (2018) 'Machining parameter optimisation for aviation aluminium-alloy thin-walled parts in high-speed milling', International Journal of Machining and Machinability of Materials, Vol. 20, No. 2, pp.180-192.

Zhang, Y., Zou, P., Li, B. and Liang, S. (2015) 'Study on optimized principles of process parameters for environmentally friendly machining austenitic stainless steel with high efficiency and little energy consumption', The International Journal of Advanced Manufacturing Technology, Vol. 79, Nos. 1-4, pp.89-99. 
2019-10-09

\section{Multi-response optimisation of}

machining aluminium-6061 under

eco-friendly electrostatic minimum

quantity lubrication environment

Jamil, Muhammad

Inderscience

Jamil M, Khan AM, He N, et al., (2019) Multi-response optimisation of machining aluminium-6061 under eco-friendly electrostatic minimum quantity lubrication environment. International Journal of Machining and Machinability of Materials, Volume 21, Issue 5-6, 2019, pp. 459-479

https://doi.org/10.1504/IJMMM.2019.103137

Downloaded from Cranfield Library Services E-Repository 